\title{
A CASE OF MULTIPLE STROKES: WHEN DEPRESSION IS BOTH A RISK FACTOR AND A COMPLICATION
}

\section{F. Znaidi, S. Ellouze, R.Gadhoum, O. Moula, R. Ghachem \\ Razi Hospital, Psychiatry « B » Departement, Tunisia}

\section{Introduction:}

Post-stroke depression ( PSD ) is a common complication in stroke rehabilitation. More recently, depression has, also, been studied as a risk factor for ischemic stroke.

\section{Objectives:}

To study the double-way relation between depression and stroke.

\section{Materials and Methods:}

- We report retrospectively the case of a patient with multiple strokes and a history of recurrent depression.

- A review of the literature using the databases "PubMed" and "ScienceDirect" and the keywords "depression", "stroke", "risk factor", "pre-stroke depression", "post-stroke depression".

\section{Results:}

- Mr. E.J, 57 years old, hospitalized in a psychiatric hospital (Razi Hospital) after a suicide attempt.

- Married, with no children (primary sterility of the couple).

- Medical history: 3 ischemic strokes (the most recent dates to 1 month before his hospitalization).

- Psychiatric history: recurrent depression with a poor compliance to treatment.

- Last hospitalization: post-stroke depression $\rightarrow$ antidepressant treatment (fluoxetine), with anxiolytic medication $\rightarrow$ two weeks after : sudden left hemiplegia.

- Imaging studies: ischemic stroke.

\section{Discussion:}

I. Depression may contribute to stroke through a variety of mechanisms:

\section{$>$ Behavioural factors:}

smoking, physical inactivity, poor diet, lack of medication compliance and obesity : increase the risk of stroke

$>$ Neuroendocrine / inflammatory factors :

\begin{tabular}{|c|c|}
\hline $\begin{array}{c}\text { sympathetic nervous system } \\
\text { activation }\end{array}$ & $\begin{array}{r}\uparrow \text { sympathetic tone } \\
\uparrow \text { blood pressure } \\
\uparrow \text { heart rate } \\
\uparrow \text { vasoconstriction } \\
\uparrow \text { platetet activation }\end{array}$ \\
\hline $\begin{array}{c}\text { dysregulation of the } \\
\text { hypothalamic-pituitary- } \\
\text { adrenocortical axis }\end{array}$ & $\begin{array}{c}\uparrow \text { ACTH } \uparrow \text { Cortisol } \\
\text { Renin Angiotensin sytem } \\
\text { activation }\end{array}$ \\
\hline $\begin{array}{c}\text { Platetlet aggregation } \\
\text { Fluid and sodium retention } \\
\text { Enflammatory cytokins: C } \\
\text { Reactive Protein , Interleukin- } \\
\text { 1, Interleukin-6, } \uparrow \text { Tumor } \\
\text { Necrosis Factor }\end{array}$ & Platelet activation \\
\hline
\end{tabular}

\section{Predictors and risk factors for PSD:}

$>$ Demographic factors:

- Age $<70$

- Female gender

$>$ Medical and psychiatric history:

- Cardiovascular diseases

- Family history of mental illness

- Personal history of depression: The rate of post-stroke depression was found to 5-6 times higher among patients with prestroke depression.

$>$ Lesion location:

- Left frontal hemisphere lesions

- Proximity to the frontal pole.

$>$ Stroke severity:

- The level of handicap is correlated with the severity of poststroke depression.

$>$ Social support:

- The number of social ties is inversely correlated with the severity of post-stroke depression.

\section{Conclusion:}

The case of our patient supports the fact that depression may be an important contributor as well as a complication of ischemic stroke. Therefore, pre-stroke depression increases odds of PSD. Early identification of patients with a history of depression and those at high risk of depression after stroke, would enable the early implementation of effective management and prevention strategies for depression and improve outcomes in these patients.

\section{References:}

1) Das J, Rajanikant GK (2018) Post stroke depression:The sequelae of cerebral stroke. Neuroscience and Biobehavioral Reviews.

2) AA Taylor, Rowan M, Momoh O et al (2018) Prevalence of prestroke depression and its association with post-stroke depression. Psychological Medicine.

3) Robert G, Robinson M.D, Ricardo E et al (2015) Post-stroke depression: a review. The American Journal Of Psychiatry

4) Roberto F.V, Frederica F, Antonio M (2018) Post-stroke depression: Mechanisms and pharmacological treatment. Pharmacology And Therapeutics.

5) Shi Y, Xiang Y, Yang Yetal (2015) Depression after minor stroke: prevalence and predictors. Journal Of Psychosomatic Research. 